\title{
Turning the Curve on Obesity Prevalence Among Fifth Graders in the Los Angeles Unified School District, 2001-2013
}

\author{
Amanda Kamali, MD${ }^{1}$; Heena Hameed, $\mathrm{MPH}^{2}$; Margaret Shih, MD, $\mathrm{PhD}^{2}$; \\ Paul Simon, MD, MPH ${ }^{3}$
}

\begin{abstract}
Suggested citation for this article: Kamali A, Hameed H, Shih M, Simon P. Turning the Curve on Obesity Prevalence Among Fifth Graders in the Los Angeles Unified School District, 2001-2013. Prev Chronic Dis 2017;14:160377. DOI: https://doi.org/10.5888/ pcd14.160377.
\end{abstract}

\section{PEER REVIEWED}

\section{Abstract}

\section{Introduction}

After multiple decades of increasing childhood obesity prevalence in the United States, findings from recent studies suggest that prevalence has leveled or is decreasing in some populations. However, demographic and socioeconomic disparities in prevalence remain and may be increasing.

\section{Methods}

To assess recent trends and disparities in childhood obesity prevalence in Los Angeles County, we analyzed data from 2001 through 2013 in fifth graders in the Los Angeles Unified School District (LAUSD). Obesity was defined as a body mass index at or above the 95th percentile for children of the same age and sex as compared with Centers for Disease Control and Prevention growth charts, on the basis of measured height and weight. Trends were examined by sex, race/ethnicity, and socioeconomic status (SES). SES was determined by using school-level data on the percentage of students participating in a free and reduced-price meal program.

\section{Results}

Obesity prevalence increased from $27.5 \%$ in 2001 to $31.6 \%$ in 2005, was stable from 2005 through 2010, and decreased from $31.6 \%$ in 2010 to $28.5 \%$ in 2013 . Similar trajectories in prevalence were observed for all demographic and SES subgroups, although the decline in prevalence began earlier among whites and students attending schools in the highest SES group. Disparities in prevalence by race/ethnicity and SES were observed during the entire study period but narrowed slightly from 2010 through 2013 .

\section{Conclusion}

Although obesity prevalence among fifth graders in LAUSD declined from 2010 through 2013, prevalence remains higher than in 2001, and demographic and socioeconomic disparities in prevalence persist. Future interventions in the county should prioritize Latinos and students attending low SES schools.

\section{Introduction}

From the late 1970s to 2000, the prevalence of childhood obesity rose rapidly throughout the United States (1). Since then, obesity prevalence has increased at a considerably slower rate among 12to 19-year-olds and has begun to decline among 6- to 11-year-olds and 2- to 5-year-olds nationally (2). Recent declines in childhood obesity prevalence have also been reported in certain states (3-5), a regional population (6), and several large cities (7-9). Despite these promising trends, racial/ethnic and socioeconomic disparities in childhood obesity prevalence remain and may be increasing $(3,5,10)$.

The Los Angeles Unified School District (LAUSD) is the secondlargest school district in the United States, with more than 500,000 students enrolled during 2013 to 2014. The district also includes the largest Latino student population in the nation, and approximately $80 \%$ of all students are eligible for participation in LAUSD's free and reduced-price meal (FRPM) program. From 2001 through 2013, childhood obesity prevention programs and policy efforts expanded in Los Angeles County. This expansion was accelerated in 2010 with funding from the Centers for Disease Control and Prevention's (CDC's) Communities Putting Prevention to Work (CPPW) initiative and CDC's Community Transformation Grant (CTG) program. We aimed to describe the changing prevalence of obesity and demographic and socioeconomic disparities in preval- 
ence among fifth graders in LAUSD during this period. This group has the highest prevalence of obesity reported among children and adolescents in Los Angeles County (11).

\section{Methods}

We analyzed fifth-grade student data collected during the spring from 2001 through 2013 via the California Physical Fitness Testing Program. The program requires annual fitness testing of all fifth, seventh, and ninth graders in all public schools, including measures of body composition, aerobic capacity, strength, and flexibility. In LAUSD, body composition is assessed by measured height and weight. Teachers or trained staff perform the height and weight measurements using standardized procedures, including removal of shoes and rounding down to the nearest inch for height and nearest pound for weight $(12,13)$. Measurements are reported by the school district to the California Department of Education (CDE). Demographic information about each student, including age (in years), sex, and race/ethnicity, is also reported. Data for 2001 through 2010 were obtained from CDE and data for 2011, 2012, and 2013 were obtained from LAUSD.

In the absence of student-level data about socioeconomic status (SES), we used, as a proxy, state data that specified percentage of students enrolled or eligible to participate in the FRPM program at each school during the fall from 2000 through $2012(14,15)$. Students attending schools with more than $75 \%$ of students enrolled in the program were classified as low SES, those attending schools with $51 \%$ to $75 \%$ enrolled were classified as middle SES, and those attending schools with $50 \%$ or less enrolled were classified as high SES. The percentage of schools in each SES group was consistent throughout the study period except in 2008, when the number of schools in the lowest SES group decreased by $15 \%$, the number in the middle group increased by $24 \%$, and the number in the highest group increased by $42 \%$. To address potential misclassification, we used an algorithm to reclassify some schools in 2008. If a school had the same SES classification throughout the study period except in 2008, we reassigned it that classification for 2008. This resulted in reclassification of $13 \%$ of schools in 2008 .

We calculated age- and sex-specific body mass index (BMI) percentiles on the basis of measured height and weight and classified students as obese ( $\geq 95$ th percentile for age and sex) using CDC growth charts (16). For the entire study period, we excluded data from the school health record with missing values $(3.6 \%$ of students) as well as height, weight, and calculated BMI values that were biologically implausible on the basis of CDC standards ( $0.7 \%$ of students) (17).

Trends in obesity prevalence were assessed by sex, race/ethnicity, and school SES. Racial/ethnic trends included whites, blacks, and
Latinos. The trend for Asian students was not calculated because of concern about misclassification; the number of students classified as Asian was considerably lower than the number of Asian students based on enrollment statistics. Trends for American Indian or Alaska Native and Native Hawaiian or Other Pacific Islander students could not be calculated because CDE did not provide their racial/ethnic information to protect student confidentiality. Statistical analysis was performed by using the Cochran-Armitage test for trend $(18,19)$. All analyses were completed by using SAS version 9.3 (SAS Institute Inc).

The study was reviewed by CDC for the purpose of human subjects' protection and deemed to be nonresearch. It was also reviewed by the Los Angeles County Department of Public Health institutional review board and certified as exempt.

\section{Results}

The number of fifth-grade students included in this analysis decreased from 56,363 in 2001 to 44,181 in 2013, paralleling a similar decline in fifth-grade enrollment during this period in LAUSD. The percentage of enrolled students included in our analysis each year (ie, reporting completeness) ranged from a low of $86 \%$ in 2010 to a high of $98 \%$ in 2006 . A small degree of variation in the demographic and socioeconomic distributions of students was observed during the study period (Table 1 ). The percentage of students that were male ranged from $50.2 \%$ to $51.2 \%$, the percentage that were Latino ranged from $70.5 \%$ to $81.6 \%$, the percentage that were black ranged from $7.3 \%$ to $12.6 \%$, and the percentage that were white range from $7.0 \%$ to $10.3 \%$. The percentage of students that attended low-SES schools ranged from $71.6 \%$ to $79.7 \%$.

The prevalence of obesity among fifth graders increased from $27.5 \%$ in 2001 to $31.6 \%$ in $2005(P<.001)$, was stable from 2005 through $2010(P=.78)$, and decreased from $31.6 \%$ in 2010 to $28.5 \%$ in $2013(P<.001)$ (Figure $1 \mathrm{~A})$. Obesity prevalence was higher among males than females throughout the study period, but the temporal trend in prevalence was similar for both groups (Figure 1B). However, the sex disparity in prevalence varied by race/ ethnicity (Figure 1C). The prevalence was higher for whites and Latinos among males than females, but among blacks the prevalence was higher among females than males. The highest prevalence was observed among Latino boys (39.6\% in 2005).

The opinions expressed by authors contributing to this journal do not necessarily reflect the opinions of the U.S. Department of Health and Human Services, the Public Health Service, the Centers for Disease Control and Prevention, or the authors' affiliated institutions. 


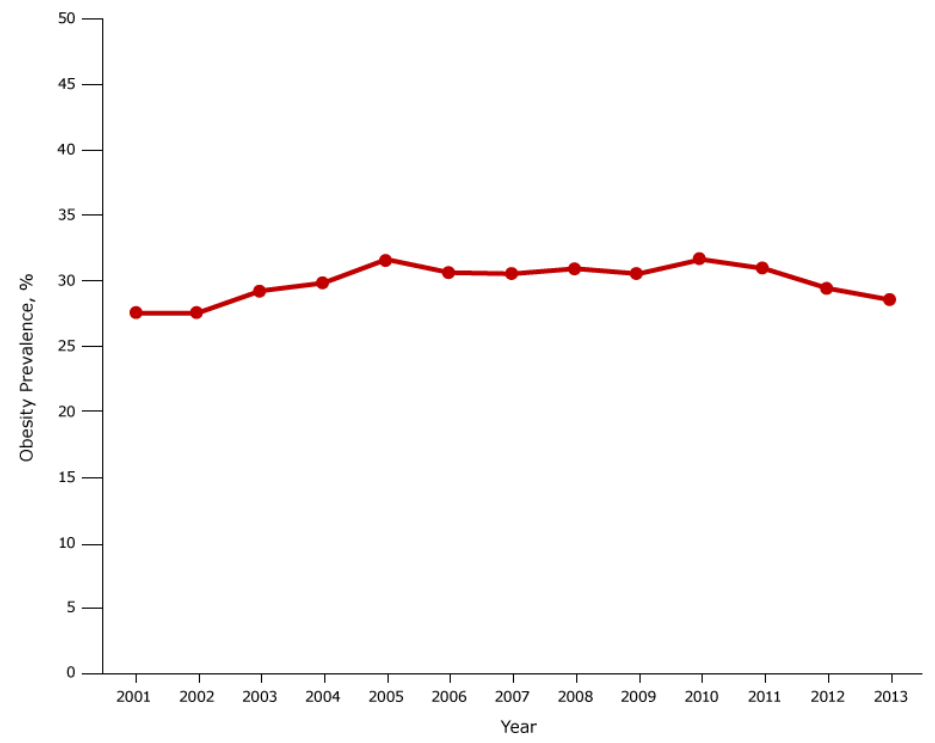

Figure 1A. Obesity prevalence among fifth-grade students, Los Angeles Unified School District, California, 2001-2013. From 2001 through 2005, obesity prevalence increased from $27.5 \%$ to $31.6 \%$. From 2010 through 2013, prevalence declined from $31.6 \%$ to $28.5 \%$.

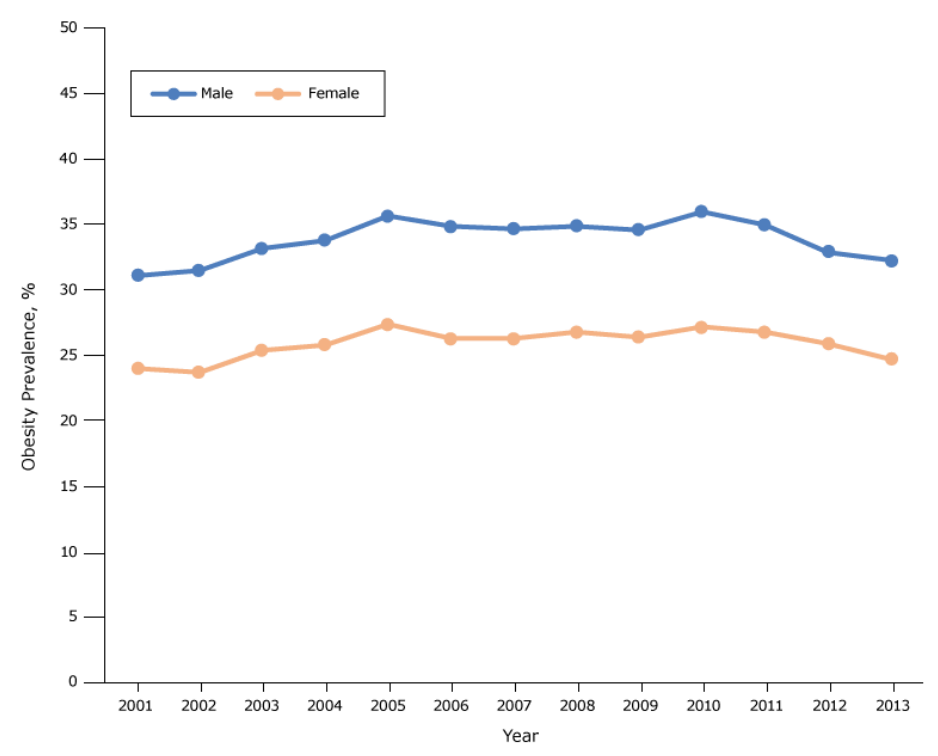

Figure 1B. Obesity prevalence among fifth-grade students, by sex, Los Angeles Unified School District, California, 2001-2013. Throughout the study period, obesity prevalence was higher among males than among females.

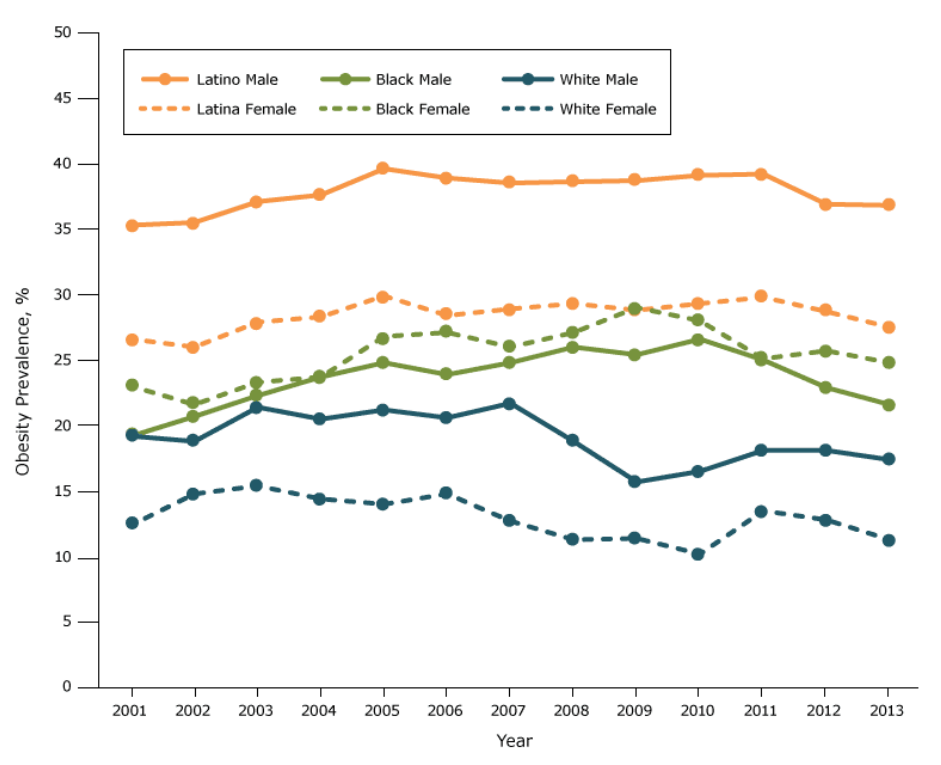

Figure 1C. Obesity prevalence among fifth-grade students, by sex and race/ethnicity, Los Angeles Unified School District, California, 2001-2013. Obesity prevalence was higher among males than females for whites and Latinos, but for blacks the prevalence was higher among females than males.

For race/ethnicity among males and females combined, obesity prevalence throughout the study period was highest among Latinos, intermediate among blacks, and lowest among whites (Figure 1D). After initial increases in prevalence among these 3 groups, prevalence declined, starting in 2003 among whites, 2010 among blacks, and 2011 among Latinos.

\footnotetext{
The opinions expressed by authors contributing to this journal do not necessarily reflect the opinions of the U.S. Department of Health and Human Services, the Public Health Service, the Centers for Disease Control and Prevention, or the authors' affiliated institutions.
} 


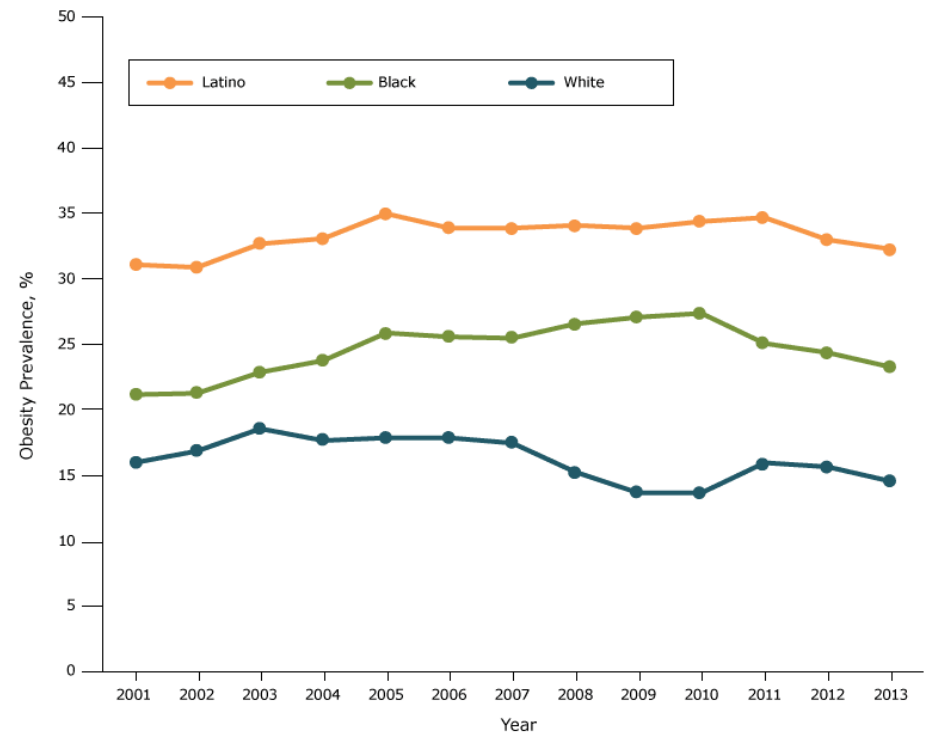

Figure 1D. Obesity prevalence among fifth-grade students, by race/ethnicity, Los Angeles Unified School District, California, 2001-2013. Throughout the study period, obesity prevalence was lowest among white students, second lowest among black students, and highest among Latino students.

For SES, obesity prevalence was highest among students in schools in the low-SES group, intermediate among those in the middle-SES group, and lowest among those in the high-SES group (Figure 2A). After initial increases in prevalence in all 3 groups, prevalence declined, starting in 2003 for those at schools in the high-SES group, 2008 for those at schools in the middle-SES group, and 2010 for those at schools in the low-SES group.

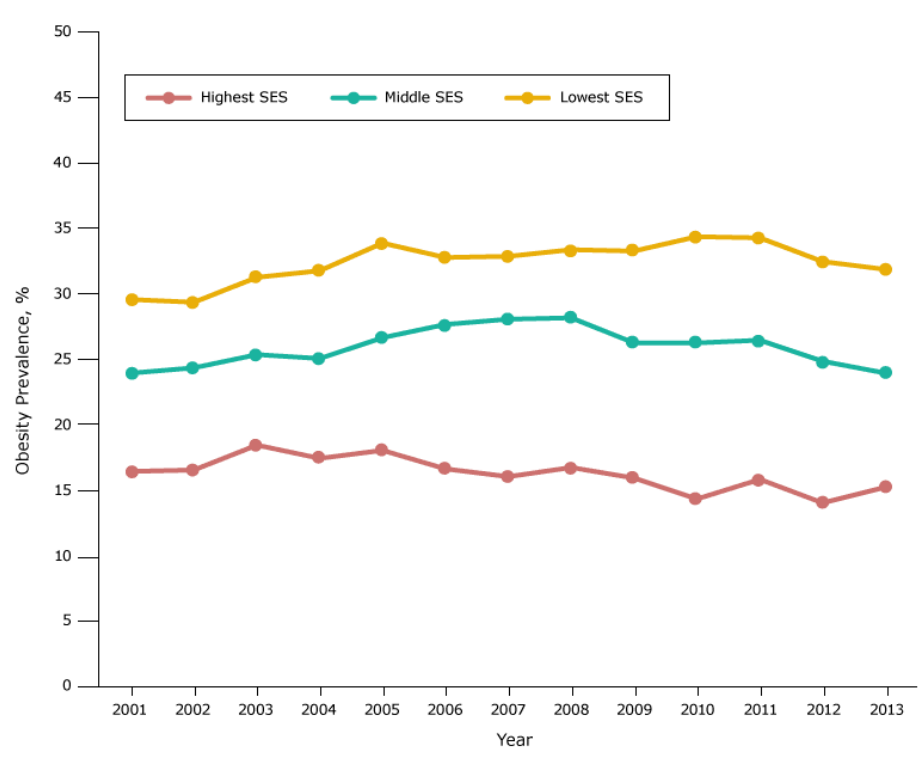

Figure 2A. Obesity prevalence among fifth-grade students, by socioeconomic status (SES), Los Angeles Unified School District, California, 2001-2013. Throughout the study period, obesity prevalence was lowest among students in the high-SES group and highest among students in the low-SES group.

In each racial/ethnic group, the obesity prevalence in most years was highest in the low-SES group, intermediate in the middle-SES group, and lowest in the high-SES group (Figures 2B-D). However, the gradient in prevalence across SES groups was largest among whites.

\footnotetext{
The opinions expressed by authors contributing to this journal do not necessarily reflect the opinions of the U.S. Department of Health and Human Services, the Public Health Service, the Centers for Disease Control and Prevention, or the authors' affiliated institutions.
} 


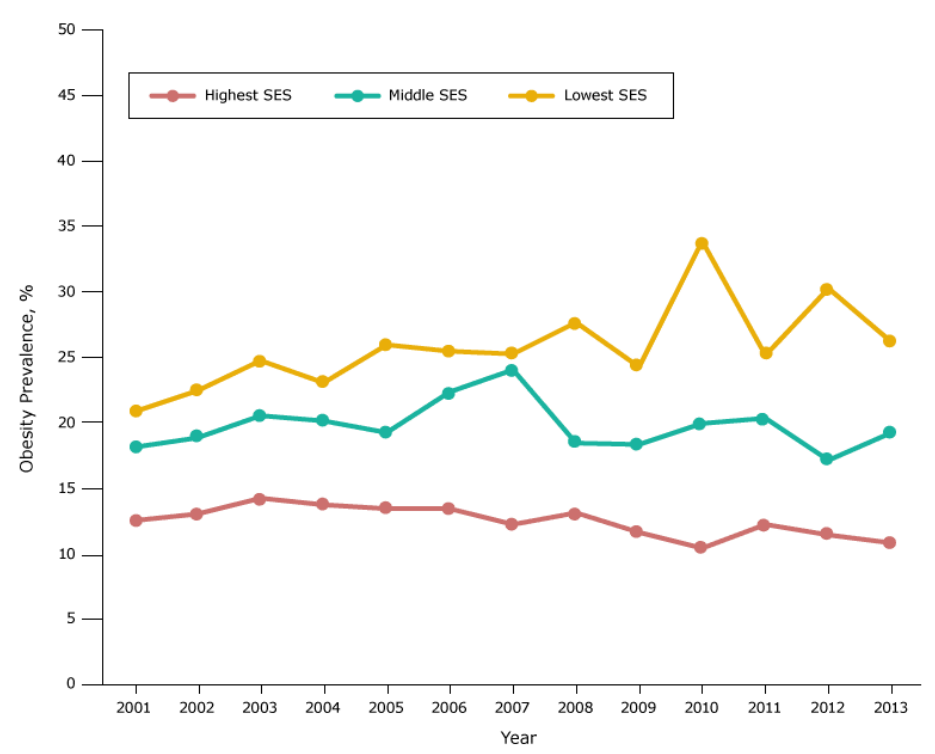

Figure 2B. Obesity prevalence among white fifth-grade students, by socioeconomic status (SES), Los Angeles Unified School District, California, 2001-2013. Throughout the study period, obesity prevalence was lowest among white students in the high-SES group and highest among white students in the low-SES group. Obesity prevalence in 2008 for white students in the low SES group should be interpreted cautiously because of the limited number of students with body mass index information.

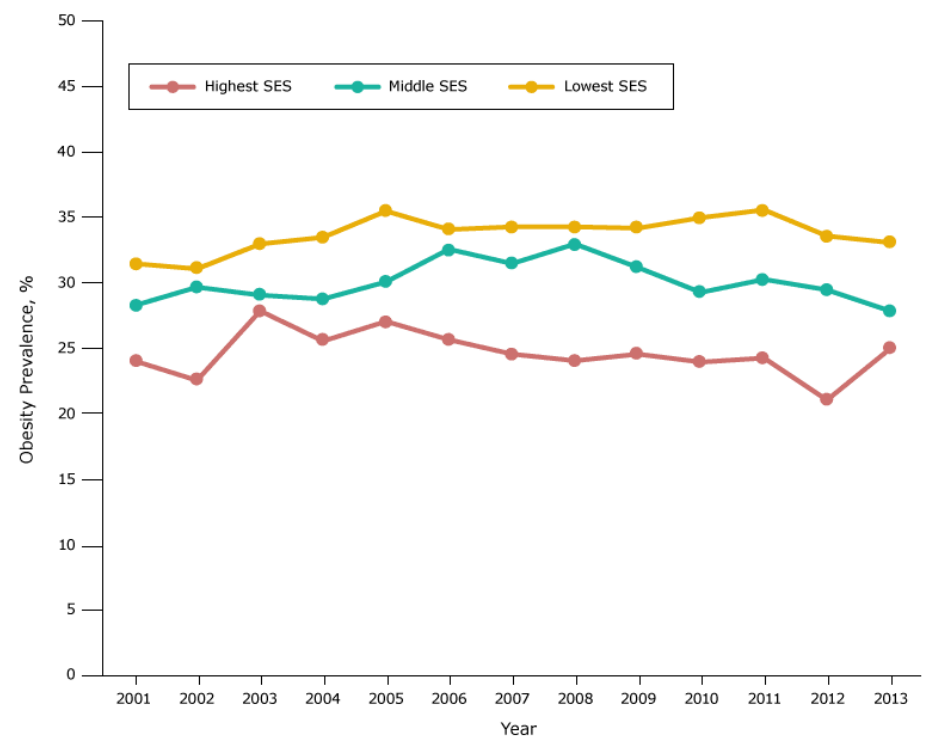

Figure 2C. Obesity prevalence among Latino fifth-grade students, by socioeconomic status (SES), Los Angeles Unified School District, California, 2001-2013. Throughout the study period, obesity prevalence was lowest among Latino students in the high-SES group and highest among Latino students in the low-SES group.

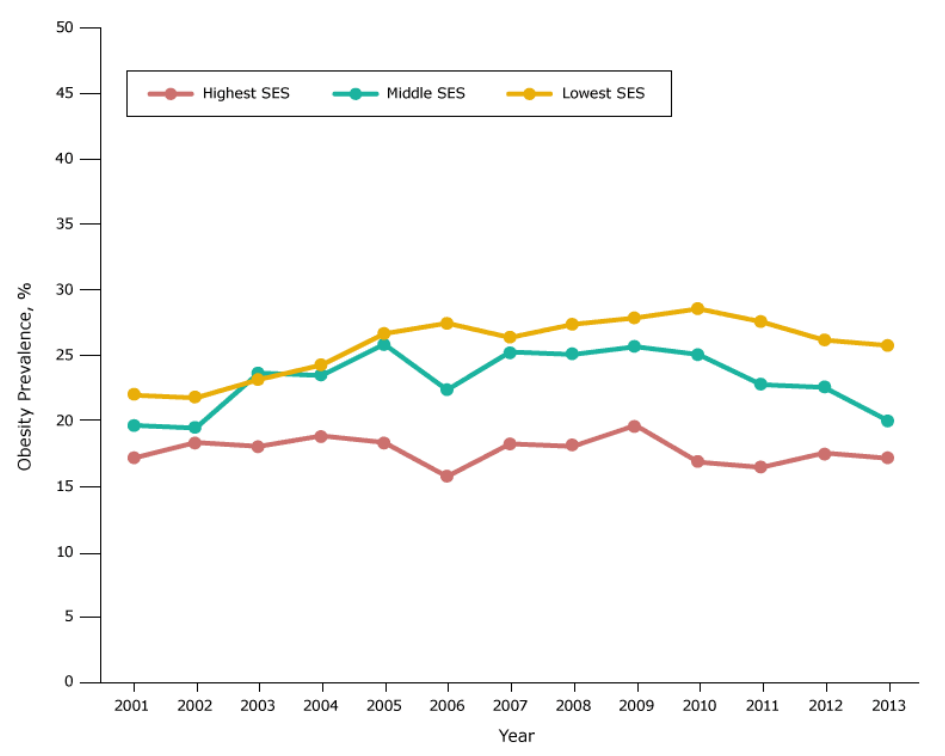

Figure 2D. Obesity prevalence among black fifth-grade students, by socioeconomic status (SES), Los Angeles Unified School District, California, 2001-2013. Throughout most years of the study period, obesity prevalence was lowest among black students in the high-SES group, and highest among black students in the low-SES group. Obesity prevalence from 2008 through 2010 for black students in the high-SES group should be interpreted cautiously because of the limited number of students with body mass index information.

During the most recent period for which data were available, 2010 through 2013, obesity prevalence declined among fifth graders overall, and a downward trend in prevalence was observed among Latino students $(P<.001)$ and black students $(P<.001)$ but not among white students. The decline in prevalence in each racial/ ethnic group was greater among children in schools in the lowSES and middle-SES groups than in the high-SES group (Table 2). For children at schools in the low-SES group, obesity prevalence was highest among Latinos (33.2\% in 2013) and similar among whites $(26.3 \%)$ and blacks $(25.9 \%)$. Among children in the highSES group, larger disparities in prevalence were observed by race/ ethnicity $(25.1 \%, 17.3 \%$, and $11.0 \%$ among Latinos, blacks, and whites, respectively, in 2013).

\section{Discussion}

From 2001 through 2013, an initial increase in obesity prevalence among fifth graders in LAUSD was followed by a leveling and then a decline in prevalence. A similar pattern was observed for all demographic and socioeconomic subgroups. The observed decline is consistent with reported declines among elementary school-aged children in New York City (8), Philadelphia (7), and the Kaiser Permanente health care system in southern California (10).

\footnotetext{
The opinions expressed by authors contributing to this journal do not necessarily reflect the opinions of the U.S. Department of Health and Human Services, the Public Health Service, the Centers for Disease Control and Prevention, or the authors' affiliated institutions.
} 
Despite this favorable trend, the obesity prevalence in our study population (28.5\%) in 2013 is above the 2001 prevalence and is considerably higher than the prevalence reported nationally (17.5\%) among 6- to 11-year-olds from 2011 through 2014 (2). We found a higher prevalence in males than females among whites and Latinos but not among blacks, a pattern that has also been reported statewide in California (5). Latino males had the highest prevalence of obesity in our study, a finding consistent with other studies, although the prevalence among Latino males reported here is far higher than has been reported elsewhere $(2,5,7)$.

We also found an inverse relationship between obesity prevalence and SES in the total study group and in each racial/ethnic group. These disparities were wide during the entire study period but narrowed slightly from 2010 through 2013 . The racial/ethnic disparities in prevalence were attenuated, although not eliminated, in low and middle socioeconomic strata, consistent with findings from other studies $(20,21)$.

Although our study was not designed to evaluate the effects of local childhood obesity prevention interventions, changes in obesity prevalence trajectories occurred during a period of expanded programmatic and policy efforts. For example, LAUSD implemented a district-wide policy in 2004 that prohibited the sale of most sugar-sweetened beverages on school campuses (22). Efforts to improve the quality of physical education across the district were initiated in 2004 with technical assistance provided to schools through the establishment of a position for a central physical education advisor. In 2005, a state policy mandated nutrition standards for all competitive foods and beverages sold on school campuses (23). These and similar efforts have been associated with reductions in childhood obesity prevalence $(24,25)$.

Local interventions were expanded in 2010 with a substantial infusion of funding through the federal CPPW initiative and continued in 2012 through CTG funding. For example, this funding supported LAUSD efforts to improve nutritional quality of school meals (26) and also helped leverage joint-use agreements to open school grounds for recreational purposes during nonschool hours (27). Additionally, intensive public education and media campaigns to reduce sugar-sweetened beverage consumption were associated with a modest decline in consumption among children in the county from 2007 through 2011 (28).

Our study has limitations. First, the analysis was limited to fifth graders in public school and may not be generalizable to other elementary school-aged children in Los Angeles County or in other jurisdictions. Second, we were unable to validate height and weight measurements in our data set; however, testing, including measurement of height and weight, was performed by staff trained in administering the fitness testing program. Third, our SES meas- ures were determined on the basis of school-level enrollment in the FRPM program and may not accurately reflect the SES of individual students. For example, in high-income schools, Latino and black children may have been more likely than whites to live in low-income households. Lastly, because our study was a descriptive analysis, we could not formally assess the effect of specific programs or policies on obesity prevalence.

Despite these limitations, our findings suggest recent progress in addressing the childhood obesity epidemic in Los Angeles County. However, prevalence remains high, and substantial disparities in prevalence persist by sex and across racial/ethnic and socioeconomic subpopulations. Given the large size of the Latino child population in the county, further progress in reducing obesity prevalence will require more effective culturally tailored interventions. These interventions should extend beyond school environments to address community conditions, particularly conditions in low-income communities that promote unhealthy diets and physical inactivity. For example, efforts are under way in Los Angeles County to reduce the marketing of unhealthy food and beverages to children (29) and to expand access to affordable produce in neighborhood markets, including neighborhoods with large concentrations of Latino residents (30). However, these efforts are unlikely to achieve the desired population-level impacts unless implemented on a large scale.

\section{Acknowledgments}

We thank Matthew Sharp, Eloisa Gonzalez, and Chad Fenwick for their insights about nutritional programs and physical education initiatives in Los Angeles County, Alex Ho for his support on the analysis, and Laurene Mascola for her editorial support. At the time of the study, Dr Kamali was with the Epidemic Intelligence Service, Centers for Disease Control and Prevention, Atlanta, Georgia, and the Los Angeles County Department of Public Health, Acute Communicable Disease Control, Los Angeles, California. The findings and conclusions in this article are those of the authors and do not necessarily represent the official position of CDC.

\section{Author Information}

Corresponding Author: Amanda Kamali, MD, Clinical Science Director, Infectious Disease, Roche Molecular Solutions, Inc, 4300 Hacienda Dr, Pleasanton, CA 94803. Telephone: 925-2516830. Email: ydh3@cdc.gov or amanda.kamali@gmail.com.

Author Affiliations: ${ }^{1}$ Epidemic Intelligence Service, Centers for Disease Control and Prevention, Los Angeles County Department of Public Health, Acute Communicable Disease Control, Los

\footnotetext{
The opinions expressed by authors contributing to this journal do not necessarily reflect the opinions of the U.S. Department of Health and Human Services, the Public Health Service, the Centers for Disease Control and Prevention, or the authors' affiliated institutions.
} 
Angeles, California. ${ }^{2}$ Los Angeles County Department of Public Health, Office of Health Assessment and Epidemiology, Los Angeles, California. ${ }^{3}$ Los Angeles County Department of Public Health, Division of Chronic Disease and Injury Prevention, Los Angeles, California.

\section{References}

1. Ogden CL, Flegal KM, Carroll MD, Johnson CL. Prevalence and trends in overweight among US children and adolescents, 1999-2000. JAMA 2002;288(14):1728-32.

2. Ogden CL, Carroll MD, Lawman HG, Fryar CD, KruszonMoran D, Kit BK, et al. Trends in obesity prevalence among children and adolescents in the United States, 1988-1994 through 2013-2014. JAMA 2016;315(21):2292-9.

3. Li W, Buszkiewicz JH, Leibowitz RB, Gapinski MA, Nasuti LJ, Land TG. Declining trends and widening disparities in overweight and obesity prevalence among Massachusetts public school districts, 2009-2014. Am J Public Health 2015; 105(10): e76-82.

4. Robert Wood Johnson Foundation. Declining childhood obesity rates: where are we seeing signs of progress? 2016. http://www.rwjf.org/content/dam/farm/reports/issue_briefs/ 2015/rwjf401163. Accessed May 17, 2016.

5. Falbe J, Cotterman C, Linchey J, Madsen KA. Ethnic disparities in trends in high BMI among California adolescents, 2003-2012. Am J Prev Med 2016;51(2):e45-55.

6. Koebnick C, Mohan YD, Li X, Young DR. Secular trends of overweight and obesity in young Southern Californians 2008-2013. J Pediatr 2015;167(6):1264-71.e2.

7. Robbins JM, Mallya G, Wagner A, Buehler JW. Prevalence, disparities, and trends in obesity and severe obesity among students in the school district of Philadelphia, Pennsylvania, 2006-2013. Prev Chronic Dis 2015;12:E134.

8. Centers for Disease Control and Prevention (CDC). Obesity in K-8 students - New York City, 2006-07 to 2010-11 school years. MMWR Morb Mortal Wkly Rep 2011;60(49):1673-8.

9. Centers for Disease Control and Prevention (CDC). Obesity prevalence among low-income, preschool-aged children New York City and Los Angeles County, 2003-2011. MMWR Morb Mortal Wkly Rep 2013;62(2):17-22.

10. Madsen KA, Weedn AE, Crawford PB. Disparities in peaks, plateaus, and declines in prevalence of high BMI among adolescents. Pediatrics 2010;126(3):434-42.

11. Los Angeles County Department of Public Health. Childhood obesity: tipping the balance toward healthy, active children. LA Health; July 2008.
12. Fitnessgram/Activitygram: test administration manual. Meredith MD, Welk GJ, editors. Updated fourth edition. Dallas (TX):The Cooper Institute; 2013.

13. California Department of Education. 2015-16 California Physical Fitness Test reference guide; 2015. http:// www.cde.ca.gov/ta/tg/pf/documents/pft15referenceguide.pdf. Accessed July 13, 2016.

14. California Work Opportunity and Responsibility to Kids (CalWORKs) data files. (2003 and prior). Sacramento (CA): California Department of Education; 2005. http:// www.cde.ca.gov/ds/sh/cw/filesafdc.asp. Accessed May 17, 2016.

15. Student Poverty Free or Reduced Price Meals 2004-2012 datasets. Sacramento (CA): California Department of Education; 2014. http://www.cde.ca.gov/ds/sd/sd/filessp.asp. Accessed May 17, 2016.

16. Kuczmarski RJ, Ogden CL, Guo SS, Grummer-Strawn LM, Flegal KM, Mei Z, et al. 2000 CDC Growth Charts for the United States: methods and development. Vital Health Stat 11 2002;(246):1-190.

17. An SAS Program for the 2000 CDC Growth Charts (ages 0 to $<20$ years). Atlanta (GA): National Center for Chronic Disease Prevention and Health Promotion, Centers for Disease Control and Prevention; 2016. http://www.cdc.gov/nccdphp/dnpao/ growthcharts/resources/sas.htm. Accessed November 1, 2016.

18. Armitage P. Tests for linear trends in proportions and frequencies. Biometrics 1955;11(3):375-86.

19. Cochran WG. Some methods of strengthening the common chi-squared tests. Biometrics 1954;10(4):417-51.

20. Rossen LM. Neighbourhood economic deprivation explains racial/ethnic disparities in overweight and obesity among children and adolescents in the U.S.A. J Epidemiol Community Health 2014;68(2):123-9.

21. Rogers R, Eagle TF, Sheetz A, Woodward A, Leibowitz R, Song $\mathrm{M}$, et al. The relationship between childhood obesity, low socioeconomic status, and race/ethnicity: lessons from Massachusetts. Child Obes 2015;11(6):691-5.

22. Los Angeles Unified School District. Guidelines for the sale of food/beverages on campus by staff, students, and parents implementing the healthy beverage and obesity prevention motions and applicable federal, state, and local laws. Los Angeles (CA): Los Angeles Unified School District; 2005. http://notebook.lausd.net/pls/ptl/docs/PAGE/CA_LAUSD/ FLDR_ORGANIZATIONS/FLDR_BUSINESS_SVCS/BUL$1908.0 \% 2 \mathrm{C} \% 20$ GUIDELINES\%20FOR $\% 20$ SALE $\% 200 F \% 2$ 0FOOD-BEVERAGES\%20ON\%20CAMPUS...\%2C\%20831-05.PDF. Accessed May 17, 2016.

The opinions expressed by authors contributing to this journal do not necessarily reflect the opinions of the U.S. Department of Health and Human Services, the Public Health Service, the Centers for Disease Control and Prevention, or the authors' affiliated institutions. 
23. California Senate. California Childhood Obesity Prevention Act; 2003. http://www.leginfo.ca.gov/pub/03-04/bill/sen/sb 0651-0700/sb_677_bill_20030917_chaptered.html. Accessed May 25, 2016.

24. Sanchez-Vaznaugh EV, Sánchez BN, Baek J, Crawford PB. "Competitive" food and beverage policies: are they influencing childhood overweight trends? Health Aff (Millwood) 2010; 29(3):436-46.

25. Sanchez-Vaznaugh EV, Sánchez BN, Crawford PB, Egerter S. Association between competitive food and beverage policies in elementary schools and childhood overweight/obesity trends: differences by neighborhood socioeconomic resources. JAMA Pediatr 2015;169(5):e150781.

26. Robles B, Wood M, Kimmons J, Kuo T. Comparison of nutrition standards and other recommended procurement practices for improving institutional food offerings in Los Angeles County, 2010-2012. Adv Nutr 2013;4(2):191-202.

27. Lafleur M, Gonzalez E, Schwarte L, Banthia R, Kuo T, Verderber $\mathrm{J}$, et al. Increasing physical activity in underresourced communities through school-based, joint-use agreements, Los Angeles County, 2010-2012. Prev Chronic Dis 2013;10:E89.

28. Simon PA, Lightstone AS, Baldwin S, Kuo T, Shih M, Fielding JE. Declines in sugar-sweetened beverage consumption among children in Los Angeles County, 2007 and 2011. Prev Chronic Dis 2013;10:E131.

29. ChangeLab Solutions. Marketing Matters: a white paper on strategies to reduce unhealthy food and beverage marketing to young children. 2015. http://www.changelabsolutions.org/ publications/marketing-matters. Accessed November 27, 2016.

30. Los Angeles Food Policy Council. Healthy Neighborhood Market Network. http://goodfoodla.org/policymaking/healthyneighborhood-market-network/. Accessed November 27, 2016.

The opinions expressed by authors contributing to this journal do not necessarily reflect the opinions of the U.S. Department of Health and Human Services, the Public Health Service, the Centers for Disease Control and Prevention, or the authors' affiliated institutions. 


\section{Tables}

Table 1. Demographic and Socioeconomic Characteristics of Fifth-Grade Students, Los Angeles Unified School District, California, 2001-2013

\begin{tabular}{|c|c|c|c|c|c|c|c|c|c|c|c|}
\hline \multirow[b]{2}{*}{ Year } & \multirow[b]{2}{*}{ No. $^{a}$} & \multicolumn{2}{|c|}{ Sex, \% } & \multicolumn{4}{|c|}{ Race/Ethnicity, \% } & \multicolumn{4}{|c|}{ School SES, \% } \\
\hline & & Male & Female & White & Latino & Black & $\begin{array}{l}\text { Other/ } \\
\text { Unknown }\end{array}$ & Lowest $^{\mathrm{b}}$ & Middle $^{c}$ & Highest $^{d}$ & Unknown ${ }^{e}$ \\
\hline 2001 & 56,363 & 50.8 & 49.2 & 10.3 & 70.5 & 12.6 & 6.6 & 75.8 & 12.2 & 11.8 & 0.2 \\
\hline 2002 & 57,883 & 50.2 & 49.8 & 9.6 & 72.0 & 12.2 & 6.3 & 77.4 & 11.7 & 10.9 & 0.0 \\
\hline 2003 & 53,270 & 50.5 & 49.5 & 9.9 & 71.4 & 12.0 & 6.7 & 76.3 & 11.8 & 11.2 & 0.7 \\
\hline 2004 & 56,726 & 51.1 & 48.9 & 8.6 & 73.7 & 11.4 & 6.4 & 79.5 & 10.6 & 9.9 & 0.1 \\
\hline 2005 & 58,110 & 50.9 & 49.1 & 8.4 & 74.2 & 10.9 & 6.5 & 78.6 & 11.0 & 10.2 & 0.1 \\
\hline 2006 & 56,566 & 51.2 & 48.8 & 8.5 & 74.3 & 10.8 & 6.5 & 79.5 & 9.5 & 10.9 & 0.1 \\
\hline 2007 & 53,012 & 51.1 & 48.9 & 8.8 & 73.6 & 10.7 & 6.9 & 76.6 & 11.5 & 11.5 & 0.4 \\
\hline 2008 & 49,453 & 51.2 & 48.8 & 7.1 & 76.2 & 7.4 & 9.3 & 75.7 & 12.0 & 11.9 & 0.4 \\
\hline 2009 & 48,001 & 51.1 & 48.9 & 7.0 & 75.8 & 7.3 & 10.0 & 75.9 & 11.5 & 12.4 & 0.3 \\
\hline 2010 & 43,919 & 51.1 & 48.9 & 7.9 & 81.6 & 7.5 & 2.9 & 79.7 & 9.8 & 10.2 & 0.2 \\
\hline 2011 & 47,648 & 51.0 & 49.0 & 9.4 & 73.9 & 9.8 & 6.9 & 72.4 & 14.3 & 13.0 & 0.3 \\
\hline 2012 & 45,567 & 50.8 & 49.2 & 9.6 & 74.1 & 9.6 & 6.7 & 74.2 & 14.1 & 11.6 & 0.2 \\
\hline 2013 & 44,181 & 51.2 & 48.8 & 9.9 & 73.6 & 9.4 & 7.1 & 71.6 & 14.0 & 14.4 & 0.0 \\
\hline
\end{tabular}

Abbreviation: SES, socioeconomic status.

${ }^{a}$ Students with valid body mass index information obtained from physical fitness testing.

${ }^{\mathrm{b}}$ Students attending schools with $>75 \%$ of students enrolled in free and reduced price meal program.

${ }^{c}$ Students attending schools with $51 \%-75 \%$ of students enrolled in free and reduced price meal program.

${ }^{d}$ Students attending schools with $\leq 50 \%$ of students enrolled in free and reduced price meal program.

${ }^{\mathrm{e}}$ Students attending schools with missing information about free and reduced price meal program participation. 
Table 2. Obesity ${ }^{a}$ Prevalence Among Fifth-Grade Students, by Race/Ethnicity and Socioeconomic Status, Los Angeles Unified School District, California, 2010-2013

\begin{tabular}{|c|c|c|c|c|c|c|}
\hline \multirow[b]{2}{*}{ Characteristic/SES Status } & \multicolumn{4}{|c|}{ Year, \% } & \multirow[b]{2}{*}{ Relative \% Change } & \multirow[b]{2}{*}{$P$ Value $^{\mathrm{b}}$} \\
\hline & 2010 & 2011 & 2012 & 2013 & & \\
\hline White & 13.6 & 15.9 & 15.6 & 14.5 & 6.6 & .53 \\
\hline Lowest $^{\mathrm{C}}$ & 34.0 & 25.3 & 30.4 & 26.3 & -22.6 & .42 \\
\hline Middle $^{d}$ & 20.1 & 20.5 & 17.3 & 19.4 & -3.5 & .38 \\
\hline Highest $^{\mathrm{e}}$ & 10.6 & 12.4 & 11.6 & 11.0 & 3.8 & .92 \\
\hline Latino & 34.3 & 34.6 & 32.9 & 32.2 & -6.1 & $<.001$ \\
\hline Lowest $^{\mathrm{C}}$ & 35.1 & 35.7 & 33.7 & 33.2 & -5.4 & $<.001$ \\
\hline Middle $^{d}$ & 29.4 & 30.4 & 29.6 & 28.0 & -4.8 & .10 \\
\hline Highest $^{\mathrm{e}}$ & 24.1 & 24.4 & 21.2 & 25.1 & 4.1 & .93 \\
\hline Black & 27.3 & 25.0 & 24.3 & 23.2 & -15.0 & $<.001$ \\
\hline Lowest $^{\mathrm{c}}$ & 28.7 & 27.7 & 26.3 & 25.9 & -9.8 & .01 \\
\hline Middle $^{d}$ & 25.2 & 22.9 & 22.7 & 20.2 & -19.8 & .02 \\
\hline Highest $^{\mathrm{e}}$ & $17.0^{f}$ & 16.6 & 17.7 & 17.3 & 1.8 & .75 \\
\hline
\end{tabular}

Abbreviation: SES, socioeconomic status.

a Obesity was defined as a body mass index $\geq 95$ th percentile, according to Centers for Disease Control and Prevention growth charts (17).

${ }^{\mathrm{b}}$ Calculated by using the Cochran-Armitage test for trend.

${ }^{\mathrm{c}}$ Students attending schools with $>75 \%$ of students enrolled in free and reduced price meal program.

${ }^{d}$ Students attending schools with $51 \%-75 \%$ of students enrolled in free and reduced price meal program.

${ }^{e}$ Students attending schools with $\leq 50 \%$ of students enrolled in free and reduced price meal program.

${ }^{f}$ Estimate should be interpreted cautiously because of the limited number of students with body mass index information in this stratum. 